\title{
The impact of trading floor closure on market efficiency: Evidence from the Toronto Stock Exchange
}

\author{
Dennis Y. CHUNG \\ Simon Fraser University \\ and \\ Karel HRAZDIL ${ }^{*}$ \\ Simon Fraser University
}

This draft: April 1, 2014

For the 2014 European Financial Management Association Conference

\begin{abstract}
:
We are the first to evaluate the impact of the trading floor closure on the corresponding efficiency of the stock price formation process on the Toronto Stock Exchange (TSX). Utilizing short-horizon return predictability as an inverse indicator of market efficiency, we demonstrate that while the switch to all electronic trading resulted in higher trading activity and lower trading costs, the information asymmetry among investors increased. The TSX trading floor closure resulted in a significant decrease in informational efficiency and it took over twenty minutes longer after floor closure for information to be incorporated into prices compared to the pre-closure period. In multivariate setting, we provide further evidence that changes in information asymmetry and increased losses to liquidity demanders due to adverse selection account for the largest variations in the deterioration of the aggregate level of informational efficiency. Our results suggest that the human element plays an important role in price discovery and electronic trading should complement, rather than replace, the exchange trading floor.
\end{abstract}

JEL Codes: G10; G14

Keywords: Electronic trading; Floor closure; Market efficiency; Toronto Stock Exchange.

\footnotetext{
* Corresponding author. Address of correspondence: Beedie School of Business, 8888 University Drive, Simon Fraser University, Burnaby, B.C., V5A 1S6, Canada; Phone: +1 778782 6790; Fax: +1 778782 4920; E-mail addresses: dychung@sfu.ca (D.Y. Chung), karel_hrazdil@sfu.ca (K. Hrazdil). We greatly appreciate the comments of Peter Klein, Nadia Massoud, and seminar participants at the 2013 International Conference on Finance and Banking, the 2013 Auckland Finance Meeting, the 2013 Australasian Finance and Banking Conference, and the 2014 Global Finance Association Conference. We acknowledge financial support from the CA Education Foundation of the Institute of Chartered Accountants of British Columbia and the Social Sciences and Humanities Research Council of Canada.
} 


\section{Introduction}

On April 23, 2013, a false report of explosions at the White House triggered an instant automated selloff of U.S. stocks and, between 1:08 pm and 1:10 pm ET, wiped out \$136 billion in market value from companies in the Standard \& Poor's 500 index. The market recovered within two minutes as human traders on the floor of the New York Stock Exchange intervened and ended the plunge. This incident has been described as a victory of human over machine, an illustration of the important role of the human element on the trading floor, and an example supporting the argument that markets need humans (Ovide, 2013; Kisling et al., 2013; Wang et al., 2013).

Over the last several decades, increasingly lower operating costs and improved time efficiencies of computer-based trading systems have forced exchanges around the world to automate trading of listed securities. Nowadays, electronic trading is the dominant method of processing and executing orders, and almost all major exchanges have completely eliminated their traditional open outcry trading floors. One of the exceptions is the New York Stock Exchange, the world's leading and largest order-driven market where the trading floor still remains active. For a long time, the NYSE has maintained that a full automation leading to the elimination of its floor would result in worse pricing for the public and that specialists still play an important role by supplying human judgment, actions, and financial capital (Freund et al., 1997). As the executive vice president of NYSE points out, "there have clearly been a lot of efficiencies and reductions in the number of people involved in trading across the whole industry. At the same time, we do think there is still a role for people to play in markets, getting involved in large situations and dampening volatility" (Armstrong, 2011). 
Whether the judgment of the exchange specialist is a human element that can be replicated by a computer was inquired in the early 70's by Black (1971a, 1971b). Since then, both theoretical and empirical studies investigated the tradeoffs between the value of human intermediation on the floor (the specialists' knowledge of the market) and the cost reduction and increased speed execution associated with automated trading technology. Specifically, prior studies analyze the effects of introduction of electronic trading and automation advancements (Freund and Pagano, 2000; Jain, 2005), compare floor traded securities with automated markets on different exchanges (Venkataraman, 2001; Battalio et al., 2007), and evaluate floor markets operating in parallel with all electronic stock exchanges (Grammig et al., 2001; Theissen, 2002; Chung and Hrazdil, 2012). The general theoretical and empirical consensus is that despite electronic trading enhances the liquidity of stock markets, there is not one type of market structure that is dominant in all circumstances and that fully automated markets could benefit from human intermediation. Finally, Aitken et al., (2004) analyze three major futures exchanges (the London International Financial Futures and Options Exchange, the Sydney Futures Exchange, and the Hong Kong Futures Exchange) that transferred trading in stock index futures from open outcry to electronic markets. The evidence from these natural floor closure experiments is that while electronic trading facilitates higher levels of liquidity and results in lower transaction costs relative to floor traded futures markets, bid-ask spreads are more sensitive to price volatility in electronically traded markets, which suggests that the performance of electronic trading systems deteriorates during periods of information arrival. Similar conclusion is reached by Tse and Zabotina (2001) who further show that before the London International Financial Futures and Options 
Exchange closed its floor, the open outcry mechanism has higher market quality and trades on the floor have higher information content.

In this paper, we contribute to this debate and provide further evidence in support of the role of the physical trading floor of a stock exchange with the human element in the price formation process. Using a proprietary dataset from the Toronto Stock Exchange (TSX), we analyze the effect of trading floor closure on the pricing efficiency of common stocks traded in an order-driven environment. The TSX experienced several events that affected trading of its securities. Ahead of NYSE, the TSX was first to introduce the Computer-Assisted Trading System (CATS) in 1977 to the trading process and was first to implement decimalization for all of its securities on April 15, 1996. Unlike the NYSE, the TSX implemented a clear-cut and complete closure of its trading floor on April 23, 1997; since then, all trading on the TSX is electronic and brokers enter their trades directly from their office desks.

The introduction of CATS and implementation of trading in decimal increments have been used as settings for natural experiments by researchers to evaluate the resulting efficiency of the price formation process (Freund et al., 1997; MacKinnon and Nemiroff, 1999; Freund and Pagano, 2000; Oppenheimer and Sabherwal, 2003; Huson et al., 2006). While findings of prior studies provide mixed evidence on whether automation significantly alters the degree of market efficiency, there are results showing strong evidence that decimalization has some desired positive impact on trading in both the US and Canada, with decrease in spreads and increase in volume of retail-sized trading. The effect of changing automation and trading speed within a market still remains, however, an important and understudied area (Hendershott and Moulton, 2011). No study has 
examined the impact of the trading floor closure on the corresponding efficiency of the stock price formation process. We fill this void and use the TSX setting to examine the effects of a clear-cut and complete switch from floor to full electronic trading. Our study is the first to document a rapid deterioration in the informational efficiency on the TSX after the switch and investigate the factors responsible for the change.

Prior literature provides mixed theoretical predictions on the informational efficiency of prices in purely electronic exchanges compared to traditional open-outcry systems. On one hand, some argue that computerized electronic trading systems can improve liquidity through lower trading costs, increased amount of publicly available information and higher transparency, which in turn reduces information asymmetry faced by market participants in real time and deters abusive practices such as insider trading and front running of customers' orders (Pagano and Roell, 1996; Jain, 2005; Stoll, 2006). Lower trading costs and higher volume further improve liquidity, which allows arbitrageurs to keep stock prices closer to their equilibrium values, and reduces barriers to market-making activity, allowing individual investors to compete with brokers that have exchange seats. On the other hand, others find that spreads are wider on the electronic exchanges than on the floor-based exchanges, as the floor trading mitigates information asymmetry and lowers the bid-ask spread because brokers build their reputations through repeated face-to-face interactions (Beneviste et al., 1992; Venkataraman, 2001; Theissen, 2002). Further, prior evidence suggests that trading floors are informationally rich; when a floor closes, the informed traders will submit orders along with the rest in the electronic market (which is anonymous) and information asymmetry increases (Pirrong, 1996). Finally, those who believe that markets are dominated by uninformed or noise traders 
argue that the low cost of trading and high turnover will lead to excessive uninformed trading driving stock prices away from their fundamental values (Shleifer and Summers, 1990). A third possibility also exists (the null hypothesis), that the efficiency of information processing will remain the same with or without the presence of trading floor. Therefore, whether and to what extent the trading floor closure impacts the informational efficiency of prices is an empirical issue, which is a main focus of this study.

The concept of market efficiency, as developed and refined by Fama (1970), in its weak, semi-strong, and strong form, provides us with a road map to evaluate the efficiency of the price formation process on the TSX. Recent developments in research on market microstructure have resulted in new approaches and opportunities for evaluating the extent to which information is incorporated in security prices. We view the market from a microstructure perspective and use the short-horizon return predictability (SHRP) approach of Chordia at el. (2008, hereafter CRS) to measure market efficiency. CRS examine two exogenous events that have decreased minimum bid-ask spreads on the New York Stock Exchange (NYSE) and test the corresponding impact of changes in liquidity on return predictability for 500 largest stocks over time. Since information is impounded in stock prices through trades (Kyle, 1985), the CRS estimation of return predictability is a more direct approach for assessing the efficiency of market makers, specialists, and arbitrageurs in processing new information. CRS are among the first to confirm that liquidity stimulates arbitrage activity, which, in turn, enhances the degree of intraday market efficiency, as evidenced by a reduction in SHRP. Overall, the SHRP characterizes the information environment and reflects the extent to which information is 
impounded in prices. CRS further encourage additional research and that "future investigation should extend the analysis to smaller firms and other years, exchanges, and countries" (p. 252). This innovative approach based on market microstructure allows us to study the impact of floor closure on the underlying efficiency of the price formation process.

Our study makes several contributions to the growing literature that examines the impact of market microstructure on asset pricing. To the best of our knowledge, we are the first study to utilize the 'SHRP from historical order flow' approach to evaluate the efficiency of the price formation process surrounding the TSX floor closure. We first demonstrate that, while the switch to all electronic trading resulted in higher volume (as more informed and uninformed traders began participating in the price formation process) and lower trading costs, the resulting information asymmetry among investors increased. Second, we extend the literature that evaluates determinants of the SHRP and document that, instead of changes in trading volume, changes in information asymmetry and increased losses to liquidity demanders due to adverse selection are most significant in accounting for the variations in the deterioration of the aggregate level of informational efficiency. Finally, while the academic literature and financial press have documented the advantages of electronic systems in day-to-day trading, there is relatively little evidence on their long-term effects. Our study documents that the TSX trading floor closure resulted in a significant decrease in informational efficiency, and took about six years of gradual improvement in efficiency to revert to the pre-all-electronic-trading level. These findings are consistent with a growing body of empirical evidence suggesting that although the electronic markets are faster and cheaper to operate and 
monitor than traditional floor-based markets, the floor-based exchanges excel at handling orders possibly motivated by private information and reputational effects (Venkataraman, 2001; Handa et al., 2004; Bessembinder and Venkataraman, 2004; Boehmer et al., 2005; Battalio et al., 2007).

Very little is currently known about how efficiently prices adjust to new information and to different information environments, and even less is known about these mechanisms in Canadian markets. The issue of market efficiency is of interest to not only market microstructure researchers, but also investors, regulators, and competing security listing venues. The analysis of TSX floor closure has important implications also for the NYSE, as both exchanges are fundamentally order-driven markets with specialists bearing market-making responsibilities. Through better understanding of the information environment and its effects, exchanges such as the NYSE will be able to enhance the price discovery of listed securities and evaluate the role of their designated market makers on the floor. In a recent Securities and Exchange Commission (2010) concept document, the commission asks questions such as: "Are there useful metrics for assessing the quality of price discovery in equity markets, such as how efficiently prices respond to new information?" and "What is the best approach for assessing whether the secondary markets are appropriately supporting the capital-raising function for companies of all sizes?" Results of our study provide direct answers and additional insights for addressing issues raised in these questions in a Canadian setting.

The rest of this paper is organized as follows. In Section 2, we provide an overview of order processing on the TSX and discuss the relevant literature. We describe the data and methods of analysis in Section 3. Empirical results are presented in Section 
4. In Section 5, we provide additional evidence on the speed of convergence to market efficiency on the TSX. We summarize and conclude the paper in Section 6.

\section{Price formation on the TSX}

The TSX today operates an auction market in the form of an electronic limit order book. Orders are listed on the basis of price-time priority and all trades are executed automatically by the system. The TSX also uses a market maker system to augment liquidity, with one registered trader serving as the market maker assigned for each stock. These market makers on the TSX have a passive role and are visible only when natural market forces cannot provide sufficient liquidity (TMX Group Limited, 2012). ${ }^{2}$

The trading environment on the TSX was very different in the pre-all-electronictrading era. The appendix shows a summary of the major activities that took place on the floor of the TSX prior to April 23, 1997. Orders were filled physically on the trading floor and a floor trader would manage a typical buy or sell order using either a passive or an active trade strategy. With a passive trade strategy, the floor trader could keep the awaiting order private or he could disclose the quantity and price at which he was willing to trade and have the information similar to that of a limit order visibly displayed at the trading post. With an active trade strategy, the floor trader would trade directly with the counterparty that posted the prevailing best bid or ask price at the trading post and execute the order yielding results similar to those generated by a market order.

A key feature of the trading floor environment on the TSX was that the floor traders' behavior was observable to each other. An observant floor trader could derive

\footnotetext{
2 For further details on electronic trading and the institutional setting of the TSX, see Anand and Subrahmanyam (2008), Oppenheimer and Sabherwal (2003), and Venkataraman (2001).
} 
valuable inferences about a trade or a stock by observing the activities of others on the trading floor. The following description provided by the Business Information Systems Department of Bell Canada in a feasibility study represents a useful portrayal of the human element in the information environment on the floor of the TSX:

... the Floor Traders work in a competitive environment. Each Trader's objective is to obtain the best price for his client. The Trader applies a considerable amount of personal discretion as to how he will negotiate an order, particularly a large order. He may choose to remain passive and fill his large order in small increments when other Traders offer stock at terms equal to or better than his. He is generally reluctant to reveal the quantity of his order lest the other Traders, in the interest of their clients, better their bid or offer prices. The Trader with the large order is also concerned that his order size may stimulate competitive orders on the same side as he is on. The dilemma in this situation is that Traders must execute large orders without revealing their size, yet when they remain passive and trade frequently in small quantities this strategy becomes obvious to other observant Traders. The observant Traders are then free to back-off or become competitive without jeopardizing their integrity. (Bell Canada, 1970, p. 27)

The observant traders' ability to identify information-based trading served as a mechanism for information to be reflected in prices enhancing the price discovery process and reducing information asymmetry in the market. ${ }^{3}$ Closure of the trading floor on April 23, 1997 changed the information environment making it no longer possible for traders to derive information from the activities on the trading floor. Therefore, on the one hand, replacing a floor-based manual system with a fully automated system could increase operational efficiency, lower costs, accommodate higher trading volume, and have a positive effect on the price discovery process. On the other hand, removal of the floor-based system might also eliminate important mechanisms that were previously available for reducing information asymmetry and enhancing price discovery. Whether

\footnotetext{
${ }^{3}$ There may also be reputational effects as described by Battalio et al. (2007) that reduce adverse selection in the non-anonymous market setting of the trading floor environment.
} 
the switch to the fully automated system had an overall positive effect on the price discovery process is an empirical question that we address in this study.

\section{Data, methods of analysis, and descriptive statistics}

\subsection{Sample}

Our sample period covers 21 months from June 1996 to February 1998, centered with the event month of April 1997 when the TSX closed its trading floor. We utilize a comprehensive dataset from the TMX Datalinx that contains a complete record of all trades and quotes for all TSX listed issues. Details include buying and selling broker numbers, volume, price, stamp time, sequence number and trade markers. To examine the impact of floor closure on the informational efficiency of the trading process, we split our sample period into two equal sub-periods (10 months). ${ }^{4}$

To be included in the final analysis, a security has to be an ordinary common stock that is actively traded (with trades during each trading day) throughout the sample period and has sufficient data to estimate various proxies for market efficiency, trading costs and informational effects (described in subsequent sections). In order to avoid extremely illiquid stocks, we eliminate stocks with month-end prices less than one dollar. Our sample selection filters result in 75 TSX firms that traded actively throughout the sample period and for which we can estimate the dependent and other control variables.

\footnotetext{
${ }^{4}$ The pre-floor closure period begins after the TSX implemented decimalization for all of its securities (on April 15, 1996). As most exchanges adopted the minimum decimal tick size, and given that prior literature evaluated the implementation of trading in decimal increments on the resulting efficiency of the price formation process (i.e. Oppenheimer and Sabherwal, 2003; Huson et al., 2006), our sample period excludes the effect of decimalization. As a sensitivity analysis, we include the event of decimalization and analyze longer time periods surrounding the TSX floor closure (i.e. 12 months and 20 months before and after the floor closure) and document comparable significant differences in the efficiency of the price formation process.
} 


\subsection{Estimation of SHRP}

Following CRS, we use a returns predictability model to measure empirically the degree of short-horizon market efficiency. The basic measure of liquidity is the bid-ask spread, the difference between the ask quote and the bid quote. We define relative effective spreads as twice the absolute value of the transaction price deviation from the midpoint of bid and ask prices, divided by the bid-ask midpoint.

First, we compute stock returns over five-minute intervals using the bid-ask midpoints quoted at the end of the intervals. We classify each trade as either a buyerinitiated or seller-initiated trade using the Lee and Ready (1991) algorithm. ${ }^{5}$ For order imbalance, we compute for each five-minute interval $t$ two measures: the number of trades $O I B \#_{t}$ and the dollar trades $O I B \$_{t}$, which we define respectively as:

$$
\begin{aligned}
& \text { OIB\# } \left.{ }_{t}=\left\{\left[\left(\begin{array}{c}
\text { Numberof } \\
\text { buyerinitiated } \\
\text { trades }
\end{array}\right]+\left(\begin{array}{c}
\text { Numberof } \\
\text { seller initiated } \\
\text { trades }
\end{array}\right]\right)\right] /\left(\begin{array}{c}
\text { Total number } \\
\text { of trades }
\end{array}\right)\right\}
\end{aligned}
$$

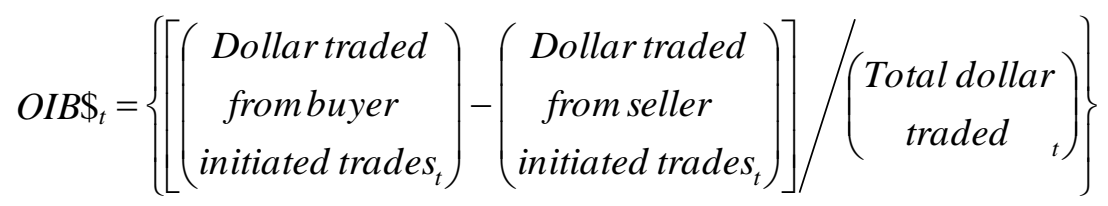

Second, unlike CRS, who analyze separately whether improved liquidity enhances informational efficiency and whether improved liquidity encourages the trading on private information in a portfolio context, we follow Chung and Hrazdil (2011) and estimate the following regression (equation 2) for each firm on a monthly basis using all

\footnotetext{
${ }^{5}$ As in CRS, we remove the requirement of the five-second delay in matching trades and quotes for periods after 1998.
} 
measures at five-minute intervals from the month. We collect the Adjusted $\mathrm{R}^{2}$ from the estimation results and use them as measures of short-horizon return predictability (SHRP). Specifically, we use the CRS's returns predictability model:

$$
\text { Return }_{t}=\alpha+\beta_{1} \text { OrderImbalance }_{t-1}+\beta_{2}\left(\text { OrderImbalance }_{t-1} * I L D_{t}\right)+\varepsilon_{t}
$$

where Return $_{t}$ is the stock return, and OrderImbalance ${ }_{t}$ is either $O I B \#_{t}$ or $O I B \$_{t}$ over the five-minute interval $t .^{6}$ Following CRS, we include the interaction variable of OrderImbalance $_{t}$ and $I L D_{t}$ to control for the effects of liquidity changes on market efficiency. We code the dummy variable, $I L D_{t}$, with a value of one for all intervals on a day if the value-weighted average effective spread for the day is at least one standard deviation above the mean spread calculated for a surrounding period over days (-60, +60 ), and zero otherwise. The t-statistic on the estimated coefficient of the lagged order imbalance variable, $\beta_{1}$, and the Adjusted $R^{2}$ from the regression (2), are both measures of return predictability and can be used as inverse proxies for short-horizon market efficiency (higher values of SHRP indicate lower levels of informational efficiency). Throughout the paper and to be consistent with prior literature, we use the Adjusted $\mathrm{R}^{2}$ as the primary measure of market efficiency. ${ }^{7}$

\subsection{Additional variable definitions}

\footnotetext{
${ }^{6}$ We report our results based the $O I B \$$. Almost identical results can be obtained using the $O I B \#$ in regression (2).

${ }^{7}$ Our univariate and regression results are virtually identical when ordinary $\mathrm{R}^{2}$ is used as a measure of market efficiency.
} 
Following prior literature, we consider several factors that are significant determinants of the SHRP. First, Chung and Hrazdil $(2010 ; 2011)$ analyze several measures of adverse selection to control for the information flow and information asymmetry effects and find that information asymmetry is positively related to $S H R P$. In our study, we define $A S_{-} L S B_{i, t}$ and $A S_{-} H S_{i, t}$ that represent the average adverse selection component of the bidask spread on a firm-by-firm basis for each month using the decomposition models of Lin et al. (1995, LSB) and Huang and Stoll (1997, HS), respectively. Both models have been shown to capture different aspects of adverse selection (Van Ness et al., 2001) and adverse selection has been shown to be negatively associated with market efficiency. To implement the LSB model, we use bid-ask spreads and transaction data from the TAQ database compiled at 30-second intervals:

$$
\Delta M_{t+1}=\lambda\left(z_{t}\right)+e_{t+1}
$$

where $\Delta M_{t+1}=M_{t+1}-M_{t} ; M_{t}$ is the quoted bid-ask spread midpoint at time $t ; z_{t}=P_{t}-M_{t}$; $P_{t}$ is the transaction price at time $t ; \lambda$ is the adverse selection component of the bid-ask spread $\left(A S \_L S B\right)$; and $e$ is a normally distributed error term. To implement the HS model, we follow Huang and Stoll and estimate the decomposition model:

$$
\Delta M_{t}=\alpha\left(\frac{S_{t-1}}{2} Q_{t-1}\right)+v_{t}
$$


where $\Delta M_{t+1}=M_{t+1}-M_{t} ; M_{t}$ is the quoted bid-ask spread midpoint at time $t ;\left(S_{t-1}\right) / 2$ is the half spread which is half the difference between the quoted ask and bid prices; $Q_{t}$ is the trade type at time $t$ and takes a value of +1 if the trade is an investor purchase and -1 if the trade is an investor sale; $\alpha$ is the combined adverse selection and inventory holding cost component of the bid-ask spread $\left(A S \_H S\right)$.

Second, Visaltanachoti and Yang (2010) report that various firm-level characteristics (including stock price, volatility, and trading volume) are significantly and negatively related to the time required to achieve market efficiency. Price and trading volume are used to capture the effects of trading costs (Stoll, 2003). In our study, we include Price (mean daily price), Volume (mean daily dollar trading volume), and Volatility (annualized volatility of daily returns) as control variables specific to the TSX exchange. We further obtain measures of effective spread, realized spread, and price impact as the first set of variables to capture the effects of trading conditions and market quality on the SHRP. Specifically, we measure effective spread (EFSpread) as the difference between the bid-ask midpoint and the actual transaction price, divided by the bid-ask midpoint. Following Hendershott et al. (2011), we further decompose EFSpread into its two components, and use the 5-minute realized spread (RZSpread) as a measure of revenue to liquidity providers, and the 5-minute price impact (PImpact) as a measure of the gross losses to liquidity demanders due to adverse selection. Specifically, for stock $i$ on trading day $j$, the corresponding measures are defined as:

$$
\begin{aligned}
& \operatorname{EFSpread}_{i, j, t}=q_{i, j, t}\left(p_{i, j, t-}-m_{i, j, t}\right) / m_{i, j, t} \\
& \operatorname{RZSpread}_{i, j, t}=q_{i, j, t}\left(p_{i, j, t}-m_{i, j, t+5 \min }\right) / m_{i, j, t}
\end{aligned}
$$




$$
\text { PImpact }_{i, j, t}=q_{i, j, t}\left(m_{i, j, t+5 \min }-m_{i, j, t}\right) / m_{i, j, t}
$$

where $p_{i, j, t}$ is the transaction price, $m_{i, j, t}$ is the bid-ask midpoint prevailing at the time of the $t^{\text {th }}$ trade, $m_{i, j, t+5 \min }$ is the bid-ask midpoint 5 minutes after the $t^{\text {th }}$ trade, and $q_{i, j, t}$ is the buy-sell indicator (with +1 for buys and -1 for sells). ${ }^{8}$ As additional proxies for bid-ask spread, we consider average dollar spread (ADSpread), average relative spread (ARSpread), and average effective spread (AESpread). ${ }^{9}$

Finally, Chung and Hrazdil (2012) analyze various informational effects (probability of informed trading, volatility, and order arrival rate of informed and uninformed traders) and show that they significantly impact the time required to achieve market efficiency. We utilize the trading model of Easley et al. (1996) which has been used to determine the probability of informed trading in high versus low volume stocks, to extract the information content of trade size and test various market microstructure models (Easley et al., 1997a; 1997b), to analyze the effect of analysts' following (Easley et al., 1998a), to examine informed traders preferred market (Easley et al., 1998b), and to test for trading on heterogeneous prior beliefs (Brockman and Chung, 2001). To control for the informational effects specific to the TSX exchange, we include PIN (probability

\footnotetext{
${ }^{8}$ Trades are classified based on the Lee and Ready (1991) algorithm. We compute, for each stock on each day, the share volume-weighted average of each measure (EFSpread, RZSpread, and PImpact). The daily measures, for each stock, are then averaged across all trading days every month during the sample period.

${ }^{9}$ Untabulated results indicate that the two proxies for adverse selection $\left(A S \_L S B\right.$ and $\left.A D \_H S\right)$ are highly correlated (Spearman and Pearson correlations exceed 0.95) and two estimates of trading volume (DVolume and SVolume) have Spearman and Pearson correlations in excess of 0.90. As a result, we report all measures variables in Table 1 (univariate analysis) and omit SVolume and AS_HS in the multivariate analysis. Their substitution does not affect our final results significantly. Finally, several estimates of bidask spreads are highly correlated (i.e. the correlations between ARSpread and AESpread and between ADSpread and AESpread exceed 0.90); we provide the sensitivity analysis of various estimates of bid-ask spreads in the multivariate analysis.
} 
of informed trading), $M U$ (order arrival rate of informed traders) and Epsilon (order arrival rate of uninformed traders) in our multivariate analysis.

The probability of informed trading model by Easley et al. (1998a) provides a method for estimating the probability of a private information event $(\alpha)$, the probability of negative news given the occurrence of a private information event $(\delta)$, the order arrival rate of informed traders $(\mu)$, and the order arrival rate of uninformed traders $(\varepsilon)$. At the beginning of every trading day, nature selects whether an information event occurs (with probability $\alpha$ ) or not (with probability $1-\alpha$ ). On non-information days, only uninformed traders participate in the market, and buy order arrivals (with arrival rate $\varepsilon$ ) are equivalent to sell order arrivals (with arrival rate $\varepsilon$ ). On private-information event days, both informed and uninformed traders enter the market. If the information event represents bad news (with probability $\delta$ ), then both informed and uniformed traders will issue sell orders (with arrival rate $\mu+\varepsilon$ ) but only uninformed traders will submit buy orders (with arrival rate $\varepsilon$ ). And if the information event represents good news (with probability 1 $\delta$ ), then both informed and uniformed traders will issue buy orders (with arrival rate $\mu+$ $\varepsilon$ ) but only uninformed traders will submit sell orders (with arrival rate $\varepsilon$ ). The arrival of buys $(B)$ and sells $(S)$ within the trading day is modeled as a combined Poisson process that can be expressed in the following likelihood function (see Easley et al., 1998a for further details):

$$
\begin{aligned}
L((B, S) \mid \alpha, \delta, \varepsilon, \mu)= & (1-\alpha) e^{-\varepsilon} \frac{\varepsilon^{B}}{B !} e^{-\varepsilon} \frac{\varepsilon^{S}}{S !}+(\alpha \delta) e^{-\varepsilon} \frac{\varepsilon^{B}}{B !} e^{-(\mu+\varepsilon)} \frac{(\mu+\varepsilon)^{S}}{S !} \\
& +\alpha(1-\delta) e^{-(\mu+\varepsilon)} \frac{(\mu+\varepsilon)^{B}}{B !} e^{-\varepsilon} \frac{\varepsilon^{S}}{S !}
\end{aligned}
$$


We obtain parameter estimates for the probability of informed trading $(\hat{\alpha})$, the

probability of bad news $(\hat{\delta})$, the order arrival rate of informed traders $(\hat{\mu})$, and the order arrival rate of uninformed traders $(\hat{\varepsilon})$ by maximizing the above likelihood function. The probability of informed trading is then given as:

$$
P I N=\hat{\alpha} \hat{\mu} /(\hat{\alpha} \hat{\mu}+2 \hat{\varepsilon})
$$

The PIN estimate is designed to capture the effects and interactions between informed and uninformed traders and measure the probability that any given trade is information based. We include the order arrival rates of the informed $(M U)$ and uninformed traders (Epsilon) to capture any incremental explanatory power these variables may have over the PIN variable.

\subsection{Summary statistics}

A summary of monthly aggregate trading activity over the sample period and the two sub-periods of the 10 trading months prior to and the 10 months after the floor closure is shown in Table 1. For each firm-month observation, we calculate and report the average SHRP along with all the proxies for information flow, information asymmetry, and trading costs defined in the previous section. Table 1 provides descriptive statistics for the 75 TSX firms for which we can estimate $S H R P$ and other control variables. The means, medians, and standard deviations of all variables suggest that all the variables follow normal distributions. The last two columns report the p-values from tests of 
differences in means and medians between the two sub-periods surrounding the floor closure. $^{10}$

\section{Insert [Table 1] about here}

Results presented in Table 1 indicate that the average level of market efficiency for the 75 actively traded TSX companies has decreased significantly when the TSX closed its trading floor. ${ }^{11}$ The average SHRP increased from 0.0383 to 0.0683 over the two periods. This change was accompanied by significant increases in informational effects and trading activity, and significant decreases in trading costs. On the one hand, the variables that experienced significant increase from the pre-closure to the post-closure period: both proxies for adverse selection; trading volume, price, volatility, and number of trades; the price impact, which captures the gross losses to liquidity demanders due to adverse selection; and the informational effects specific to the TSX exchange (order arrival rate of informed traders and order arrival rate of uninformed traders). On the other hand, several different measures of spreads (ADSpread, ARSpread and RZSpread, which captures and the revenue to liquidity providers) experienced significant decrease from the pre-closure to the post-closure period. The significant increase in the order arrival rate of informed traders and order arrival rate of uninformed traders also resulted in overall significant decrease in the probability of informed trading. This finding is contrary to

\footnotetext{
${ }^{10}$ We use the parametric two-sample t-test and the nonparametric Wilcoxon-Mann-Whitney test for differences in means and medians respectively,

${ }^{11} \mathrm{We}$ report results based on a period length of 10 months for both the pre- and post-closure periods. We also repeat our analysis using longer period lengths (e.g., 27 and 20 months) and the overall results remain the same. As additional tests for sensitivity, we also consider shorter time periods (e.g. 6 months) surrounding the floor closure and document even more significant changes in market efficiency (results not tabulated).
} 
Grammig et al. (2001) who analyze the floor and the screen trading systems operating in parallel find that the probability of informed trading is significantly lower in the floor based trading system.

Figure 1 provides graphical illustration of monthly return predictability changes over our sample period. There is an evident increase in SHRP (decrease in market efficiency) surrounding the TSX floor closure in April 1997, which takes over several years to revert back to its pre-all-electronic-trading level. It is also evident from the figure that the implementation of decimalization for the TSX securities in April 1996 resulted in the improvement in market efficiency. ${ }^{12}$

Insert [Figure 1] about here

The figure is based on 75 stocks for which we have all control variables available during the period from 10 trading months prior to floor closure to 10 months after the floor closed. Figure 1 tracks these 75 stocks further over the next twelve years to provide visual illustration on the market efficiency over time.

To provide numerical evidence on the time over which the market efficiency reverted back to its pre-all-electronic-trading level, we isolate 39 stocks that traded during the 1995 to 2004 inclusive. Table 2 provides evidence that the TSX trading floor closure resulted in a significant decrease in informational efficiency, which returned to its

\footnotetext{
${ }^{12}$ Since this paper focuses on the TSX floor closure, we do not provide a comprehensive analysis of the implementation of decimalization for the TSX securities. Untabulated results show that the average SHRP dropped from 0.0415 during May 1995 to March 1996 to 0.0363 during May 1996 to March 1997 (difference significantly different $\mathrm{p}$-value 0.0134 ); the median values during the same period dropped from 0.0309 to 0.0237 (difference significantly different p-value 0.0006 ). This evidence contributes to prior literature that the decimalization had a positive effect on the price formation process of the TSX securities.
} 
pre-all-electronic-trading level in about five years (five years based on analysis of means, six/seven years based on analysis of medians).

\section{Insert [Table 2] about here}

We provide additional evidence on the speed of convergence to market efficiency on the TSX before and after the trading floor closure. We repeat the estimation of the returns predictability model using different lengths of time in the specification of the model and utilize the refined approach described in Chung and Hrazdil (2012) to identify the time interval over which order imbalances are no longer significant in explaining short-horizon returns. We use the same 72 k-minute intervals as in Chung and Hrazdil (2012), with the minimum length set at the one-minute interval and the maximum length at the 120-minute interval. This approach builds on the original work of Chordia et al. (2008) to obtain a speed of convergence measure, starting with the shortest interval, moving to the next longer interval one at a time, and identifying the interval where order imbalance first becomes insignificant. Chung and Hrazdil (2012) use this interval as the lower bound (LB) and introduce a refinement by continuing to check all the remaining longer intervals and locating an upper bound (UB) for a possible range of the speed of convergence. Following Chung and Hrazdil (2012), we use the midpoint of this range as an estimate of the speed of convergence to market efficiency (Speed). We obtain the Speed measure for 69 of our 75 sample firms over a comparable period before and after the trading floor closure periods. The results reveal that it took on average about 47 minutes (41 minutes based on median) in the pre-closure period and 69 minutes (67 
minutes based on median) in the post-closure period for information to be incorporated into prices. The significantly longer time (22 minutes and 26 minutes based on differences in means and medians, respectively) that was needed to achieve informational efficiency in the post-closure period provides further evidence strongly supportive of our main result that the complete closure of the trading floor resulted in a significant decrease in market efficiency on the TSX.

\section{Multivariate results}

Table 3, Panel A, reports the Pearson (above diagonal) and Spearman (below diagonal) correlations among the tested variables, further providing evidence and confirming the hypothesized association of certain variables. For example, proxies for trading costs (volume, price, spread) are significantly correlated with each other and also with firm market efficiency. Also, as expected, trading volume is highly correlated with the order arrival rate of informed traders, order arrival rate of uninformed traders, and the number of trades. Similar associations were documented by Chung and Hrazdil (2010, 2011, and 2012). Overall, the correlations show that the market efficiency is significantly correlated with all of its theoretical determinants. For completeness, Panel B reports Pearson (above diagonal) and Spearman (below diagonal) correlations of changes in variables between Period 1 and Period 2 calculated based on averages for each of the 75 stocks in our sample.

Insert [Table 3] about here 


\subsection{Determinants of changes in market efficiency}

In order to determine which variables account for the largest variations in the deterioration of the aggregate level of informational efficiency from the pre-closure to the post-closure period, we calculate changes in the explanatory variables over the two equal time periods and estimate the following cross-sectional regression model:

$$
\begin{aligned}
& \Delta \text { SHRP }_{i}=\alpha+\beta_{1} \Delta A S_{-} L S B_{i}+\beta_{2} \Delta \text { EFSpread }_{i}+\beta_{3} \Delta \text { RZSpread }_{i}+\beta_{4} \Delta \text { PImpact }_{i}+ \\
& +\beta_{5} \Delta \text { DVolume }_{i}+\beta_{6} \Delta \text { NTrades }_{i}+\beta_{7} \Delta \text { Volatility }_{i}+\beta_{8} \Delta \text { Price }_{i}+ \\
& +\beta_{9} \Delta M U_{i}+\beta_{10} \Delta \text { Epsilon }_{i}+\beta_{11} \Delta P I N_{i}+\varepsilon_{i}
\end{aligned}
$$

The dependent variable is an inverse measure of the market efficiency; therefore, increases in SHRP are interpreted as deteriorations the price formation process over the period. Table 4, Panel A, presents the bivariate regression results. It is evident from models 1-11 that, of the eleven variables, increases in adverse selection (AS_LSB) explain over $36 \%$ of the variations in changes in $S H R P$. Along with increases in $A S_{-} L S B$, increases in losses to liquidity demanders due to adverse selection (PImpact) also have significant impact on the deterioration of market efficiency over the two periods; changes in $A S \_L S B$ and PImpact are also significantly correlated with one another. Other significant determinants of the changes in market efficiency include number of trades (NTrades) and order arrival rate of informed and uninformed traders (MU and Epsilon respectively), which also individually explain over $15 \%$ of the variations in SHRP. Increased participation from informed and uninformed traders (who submit more trades and increase trading volume) improves the efficiency of the price formation process (as 
evident from Table 3, Panel A). The negative correlations between $A S \_L S B$ and $M U$, Epsilon, and NTrades (as well as their respective changes) suggest that higher participation from informed and uninformed traders reduces information asymmetry; however, the TSX floor closure resulted in higher information asymmetry, which cannot be explained by any of the tested variables. Which of the explanatory variables remains significant in the multivariate setting is reported in Table 4.

Insert [Table 4] about here

Due to high correlations between EFSpread and its components (RZSpread and PImpact) and between MU, Epsilon (components of PIN) and NTrades in Table 3, we carry out our multivariate analyses using different sets of variables in each model. For example, models 12-15 in Panel B of Table 4 incorporate $\triangle E F S p r e a d$, whereas models 17-20 incorporate the components of the effective spread (ARZSpread and APImpact). Results in Panel B of Table 4 show that overall the estimated coefficients and significance of variables are very stable across the different models providing some evidence that our results are not seriously affected by the problem of multicollinearity in the data. Across the models, changes in information asymmetry $\left(\triangle A S_{-} L S B\right)$ and price (APrice) are the two variables that remain significant consistently in the multivariate setting after the effects of all other variables have been controlled for. Among these variables, the change in information asymmetry is the most significant contributor to the variation in market efficiency. When the components of the effective spread are introduced separately as additional repressors in models 17-20 in Panel B, their inclusion 
raises the overall $\mathrm{R}^{2}$ of all models. In addition to changes in information asymmetry, the increase in gross losses to liquidity demanders due to adverse selection (APImpact) is a significant determinant of the deterioration of market efficiency over the period. Together, $\triangle A S \_L S B$ and $\triangle P$ Impact explain over $55 \%$ of the variation in $\triangle S H R P$ (based on Model 16). Untabulated results indicate that all remaining variables individually add only marginal increase in the $\mathrm{R}^{2}$.

As all our proxies for the bid-ask spread did not experience a uniform decrease over the two periods, we analyze the different spreads in multivariate regressions. As a sensitivity analysis, models in Panel $\mathrm{C}$ of Table 4 separately incorporate $\triangle A D$ Spread, $\triangle A E S p r e a d$, and $\triangle A R$ Spread. The results suggest that neither definition of spread is significantly associated with the deterioration of the efficiency of the price formation process.

Overall, while the improvements in trading costs and trading activity (i.e. volatility, price, number of trades, and order arrival rates of informed and uninformed traders) contribute to improvements in market efficiency over the periods, the resulting increase in information asymmetry and price impact have a stronger opposite effect on the efficiency of price formation process.

Our findings appear to be consistent with the proposition that while the electronic trading can facilitate higher levels of liquidity and lower transaction costs relative to floor traded markets, the lack of specialists (floor brokers) in anonymous markets increases adverse selection in trading, which hampers the performance of electronic trading systems during periods of information arrival (Aitken et al., 2004; Anand and Subrahmanyam, 2008). Further, traditional market microstructure literature (Kyle, 1985) 
largely views market intermediaries as uninformed traders who cover their losses to informed traders by charging the adverse selection component of the bid-ask spread. As market intermediaries possess important order flow information that gives them an informational advantage (Madhavan and Panchapagesan, 2000), the electronic setup of the TSX after the floor closure reduces the specialists' informational advantages over other traders, which likely increases losses to liquidity demanders due to adverse selection.

\section{Summary and conclusions}

Evidence around the world suggests that exchanges are moving away from floor-based trading to all-electronic trading platforms. Both theoretical arguments and empirical evidence suggest that neither structure is clearly superior. While electronic trading yields considerable cost saving over traditional floor-based system, the professional relationships among traders and the human element on the trading floor may enhance information sharing and price discovery resulting in reduction in information asymmetry. We contribute to this debate and provide further evidence in support of the role of the physical trading floor with the human element in the price formation process.

Using proprietary data from the Toronto Stock Exchange, we examine the impact of the trading floor closure on the corresponding efficiency of the stock price formation process in an order-driven environment. We rely on recent advancements in market microstructure and utilize the short-horizon return predictability as an inverse indicator of market efficiency to demonstrate that the TSX trading floor closure resulted in a significant decrease in informational efficiency. Additional results show that it took on 
average over twenty minutes longer after floor closure for information to be incorporated into prices compared to the pre-closure period. We evaluate various proxies for trading activity, trading costs, and informational effects and find that while the switch to all electronic trading resulted in higher volume and lower trading costs, the informational efficiency of the market deteriorated and the information asymmetry among investors increased as more informed and uninformed traders entered the market. In multivariate setting, we provide further evidence that changes in information asymmetry and increased losses to liquidity demanders due to adverse selection account for the largest variations in the deterioration of the aggregate level of informational efficiency. Finally, our results show that the efficiency of the price formation process on the TSX returned to its pre-all-electronic-trading level in about six years.

Our results have important implications for the debate between proponents of the floor and the screen-based systems, which is of particular interest to regulators, investors, and stock exchanges. Our results suggest that the human element plays an important role in price discovery and electronic trading should complement, rather than replace, the exchange trading floor. 


\section{Appendix}

\section{Order processing on the trading floor of the TSX}

Prior to the switch to electronic trading on April 23, 1997, the trading floor of the TSX was a place full of activity. ${ }^{13}$ Order entry and execution began with a desk trader in the office of a brokerage firm, a member firm of the TSX, sending a buy or sell order by telephone to a phone clerk located in a booth on the perimeter of the trading floor. The phone clerk recorded the order information on an order slip and passed the slip to a floor trader. The floor trader would then proceed to the trading post where the security was traded and evaluate the bid and ask prices that were displayed on the post face. At the same time, the floor trader would be observing the activities and behavior of other traders on the trading floor, and might consult or negotiate with other traders if necessary. With past experience and all the available information, the floor trader would make a decision following either a passive trade strategy or an active trade strategy with respect to this particular order.

In the case of a passive trade strategy, the floor trader could choose to wait for further developments without disclosing his bid or ask price. Alternatively, he could choose to disclose his bid or ask price by forwarding his offer to the post boy at the trading post. The post boy would then make a chalk notation of the offer together with the trader's identification on the post face. The floor trader would then file the passive order in his order book and wait for other traders to meet his terms.

In the case of an active trade strategy, the floor trader was willing to trade at the prevailing best bid or ask price displayed at the trading post. The floor trader stood in the

\footnotetext{
${ }^{13}$ We summarize the trading floor activities based on the detailed description provided in a feasibility study report to the TSX by the Business Information Systems Department of Bell Canada (1970).
} 
trading square opposite the post face and shouted the identification number of the trader who posted the best bid or ask price. The passive trader, upon hearing his number being called, made his way to the shouting active trader. The two traders met in the trading square and the active trader executed his order buying from or selling to the passive trader. The selling trader filled out a trade slip which the buying trader initialed. Each trader retained one copy of the trade slip and another copy was passed to the post boy. The post boy time stamped the slip, put it in a carrier, and dispatched the unit to the ticker clerks. Both traders updated their order books, recorded the traded price and quantity on their order slips, and sent the order slips to their respective phone clerks who in turn telephoned the executed order data to the desk traders in their own offices. The active floor trader might have to repeat these procedures a number of times with several passive traders to trade the full quantity of his order.

Market information was displayed on the trading floor at two specific locations: the trading posts and the "Ticker" displays. The trading posts showed the bid and ask prices, by security, on the post face next to each permanently displayed stock identification symbol. The post boy maintained the market information displayed on the post faces and updates the bid and ask prices as instructed by the floor traders. When a trader submitted a bid or ask price that was better than an existing price, the post boy telephoned a teleregister clerk who typed the data into the electronic teleregister equipment updating the mechanical numerical display on the post face with the new best bid or ask price. The post boy verified the information on the mechanical display and printed the trader identification number beside it. The "Ticker" was a travelling message wall display board that provided a temporary display of the price and quantity of each 
board lot transaction in a security. The ticker clerks read the trade slips received from the post boy, typed the trade information on a keyboard machine, and produced a punched paper tape. The paper tape was then used for feeding data to the "Ticker" displays and for saving trade data to a Ferranti Packard Computer. The computer maintained a diary of trade reports for the subsequent processing of clearing, surveillance, and statistical reports. The computer also supported a CANDAT market information inquiry system providing floor traders with information such as volumes, last trade prices, and most active stocks, through inquiry devices that were installed on the trading floor. 


\section{References}

Aitken, M., Frino, A., Hill, A. and Jarnecic, E. 2004. "The impact of electronic trading on bid-ask spreads: Evidence from futures markets in Hong Kong, London, and Sydney", Journal of Futures Markets, Vol. 24, No. 7, pp. 675-696.

Anand, A. and Subrahmanyam, A. 2008. "Information and the intermediary: Are market intermediaries informed traders in electronic markets?". Journal of Financial and Quantitative Analysis, Vol. 43, No. 1, pp. 1-28.

Armstrong, J. 2011. "Designated market making alive and well at NYSE", Traders $\begin{array}{llll}\text { Magazine } \quad \text { Online } & \text { News), }\end{array}$ http://www.tradersmagazine.com/news/market-maker-nyse-trading-1096841.html.

Battalio, R., Ellul, A. and Jennings, R. 2007. "Reputation effects in trading on the New York Stock Exchange”, Journal of Finance, Vol. 62, No. 3, pp. 1243-1271.

Bell Canada, Business Information Systems Department. 1970. Computer Assisted Trading: A Feasibility Study for the Toronto Stock Exchange.

Beneviste, L., Marcus, A. and Wilhelm, W. 1992. "What's special about the specialist?" Journal of Financial Economics, Vol. 32, No. 1, pp. 61-86.

Bessembinder, H. and Venkataraman, K. 2004. "Does an electronic stock exchange need an upstairs market?" Journal of Financial Economics, Vol. 73, No. 1, pp. 3-36.

Black, F. 1971a. "Toward a fully automated stock exchange, Part I", Financial Analysts Journal, Vol. 27, No.4, pp. 28-44.

Black, F. 1971b. "Toward a fully automated stock exchange, Part II”, Financial Analysts Journal, Vol. 27, No. 6, pp. 24-28, 86-87. 
Boehmer, E., Saar, G. and Yu, L. 2005. "Lifting the veil: An analysis of pre-trade transparency at the NYSE", Journal of Finance, Vo. 60, No. 2, pp. 783-816.

Brockman, P. and Chung, D. 2001. "An empirical investigation of trading on asymmetric information and heterogeneous prior beliefs", Journal of Empirical Finance, Vo. 7, No. 5, pp. 417-454.

Chordia, T., Roll, R. and Subrahmanyam, A. 2008. "Liquidity and market efficiency", Journal of Financial Economics, Vo. 87, No. 2, pp. 249-268.

Chung, D. and Hrazdil, K. 2010. "Liquidity and market efficiency: A large sample study”, Journal of Banking \& Finance, Vol. 34, No. 10, pp. 2346-2357.

Chung, D. and Hrazdil, K. 2011. "Market efficiency and the post-earnings announcement drift”, Contemporary Accounting Research, Vol. 28, No. 3, pp. 926-956.

Chung, D. and Hrazdil, K. 2012. "Speed of convergence to market efficiency: The role of ECNs", Journal of Empirical Finance, Vol. 19, No. 5, pp. 702-720.

Easley, D., Kiefer, N., O’Hara, M. and Paperman, J. 1996. "Liquidity, information, and infrequently traded stocks", Journal of Finance, Vol. 51, No. 4, pp. 1405-1436.

Easley, D., Kiefer, N. and O'Hara, M. 1997a. “One day in the life of a very common stock", Review of Financial Studies, Vol. 10, No. 3, pp. 805-835.

Easley, D., Kiefer, N. and O'Hara, M. 1997b. “The information content of the trading process", Journal of Empirical Finance, Vol. 4, No. 2, pp. 159-186.

Easley, D., O'Hara, M. and Paperman, J. 1998a. "Financial analysts and informationbased trade", Journal of Financial Markets, Vol. 1, No. 2, pp. 175-201. 
Easley, D., O’Hara, M. and Srinivas, P. 1998b. "Option volume and stock prices: Evidence on where informed traders trade", Journal of Finance, Vol. 53, No. 2, pp. 431-465.

Freund, W., Larrain, M. and Pagano, M. 1997. "Market efficiency before and after the introduction of electronic trading at the Toronto Stock Exchange", Review of Financial Economics, Vol. 6, No. 1, pp. 29-56.

Freund, W. and Pagano, M. 2000. "Market efficiency in specialist markets before and after automation”, Financial Review, Vol. 35, No. 1, pp. 79-104.

Grammig, J., Schiereck, D. and Theissen, E. 2001. "Knowing me, knowing you: Trader anonymity and informed trading in parallel markets", Journal of Financial Markets, Vol. 4, No. 3, pp. 385-412.

Handa, P., Schwartz, R. and Tiwari, A. 2004. "The economic value of a trading floor: Evidence from the American Stock Exchange”, Journal of Business, Vol. 77, No. 2, pp. 331-355.

Hendershott, T. and Moulton, P. 2011. "Automation, speed, and stock market quality: The NYSE’s Hybrid”, Journal of Financial Markets, Vol. 14, No. 4, pp. 568-604. Hendershott, T., Jones, C. and Menkveld, A. 2011. "Does algorithmic trading improve liquidity?" Journal of Finance, Vol. 66, No. 1, pp. 1-33.

Huang, R. and Stoll, H. 1997. "The components of the bid-ask spread: A general approach", Review of Financial Studies, Vol. 10, No. 4, pp. 995-1034.

Huson, M. Kim, Y. and Mehrotra, V. 2006. "Did decimalization benefit members of the Toronto Stock Exchange?" Quarterly Journal of Business and Economics, Vol. 45, No. 3-4, pp. 49-69. 
Jain, P. 2005. "Financial market design and the equity premium: Electronic versus floor trading”, Journal of Finance, Vol. 60, No. 6, pp. 2955-2985.

Kisling, W., Lam, E., and Mehta, N. 2013. "Human beats machine this time as fake report roils stocks", Bloomberg News (April 23), http://www.bloomberg.com/news/2013-04-24/human-beats-machine-this-time-asfake-report-roils-stocks.html.

Kyle, A. 1985. "Continuous auctions and insider trading", Econometrica, Vol. 53, No. 6, pp. 1315-35.

Lee, C. and Ready, M. 1991. "Inferring trade direction from intraday data", Journal of Finance, Vol. 46, No. 2, pp. 733-747.

Lin, J., Sanger, G. and Booth, G. 1995. "Trade size and components of the bid-ask spread", Review of Financial Studies, Vol. 8, No. 4, pp. 1153-1183.

MacKinnon, G. and Nemiroff, H. 1999. "Liquidity and tick size: Does decimalization matter?" Journal of Financial Research, Vol. 22, No. 3, pp. 287-299.

Madhavan, A., and Panchapagesan, V. 2000. "Price discovery in auction markets: A look inside the black box", Review of Financial Studies, Vol. 13, No. 3, pp. 627-658.

Oppenheimer, H. and Sabherwal, S. 2003. "The competitive effects of US decimalization: Evidence from the US-listed Canadian stocks", Journal of Banking \& Finance, Vol. 27, No. 9, pp. 1883-1910.

Ontario Securities Commission. 2011. "Notice of proposed national instrument 23-103 electronic trading and direct electronic access to marketplace”, No. 23-103 (April $8)$, http://www.osc.gov.on.ca/documents/en/SecuritiesCategory2/ni_20110408_23-103_pro-electronic-trading.pdf. 
Ovide, S. 2013. "False AP twitter message sparks stock market selloff", Wall Street Journal (April

23), http://online.wsj.com/article/SB1000142412788732373560457844097157489701 6.html.

Pagano, M. and Roell, A. 1996. “Transparency and liquidity: A comparison of auction and dealer markets with informed trading", Journal of Finance, Vol. 51, No. 2, pp. 579-611.

Pirrong, C. 1996. "Market liquidity and depth on computerized and open outcry trading systems: A comparison of DTB and LIFFE bund contracts", Journal of Futures Markets, Vol. 16, No. 5, pp. 519-543.

Shleifer A. and Summers, L. 1990. "The noise trader approach to finance", Journal of Economic Perspectives, Vol. 4, No. 2, pp. 19-33.

Stoll, H. 2003. "Market microstructure", Handbook of the Economics of Finance, Vol. 1, Part A, pp. 553-604.

Stoll, H. 2006. "Electronic trading in stock markets", Journal of Economic Perspectives, Vol. 20, No. 2, pp. 153-174.

Theissen, E. 2002. "Price discovery in floor and screen trading systems", Journal of Empirical Finance, Vol. 9, No. 4, pp. 455-474.

TMX Group Limited. 2012. Market Making System (January 17), http://www.tmx.com/en/trading/products_services/market_system.html.

Tse, Y. and Zabotina, T. 2001. "Transaction costs and market quality: Open outcry versus electronic trading", Journal of Futures Markets, Vol. 21, No. 8, pp. 713-735. 
Van Ness, B., Van Ness, R. and Warr, R. 2001. "How well do adverse selection components measure adverse selection?” Financial Management, Vol. 30, No. 3, pp. 77-98.

Venkataraman, K. 2001. "Automated versus floor trading: An analysis of execution costs on the Paris and New York exchanges”, Journal of Finance, Vol. 56, No. 4, pp. $1445-1485$.

Visaltanachoti, N. and Yang, T. 2010. "Speed of convergence to efficiency for NYSElisted foreign stocks", Journal of Banking \& Finance, Vol. 34, No. 3, pp. 594605.

Wang, L., Kisling, W., and Lam, E. 2013. "Fake tweet erasing \$136 billion shows marks need humans", Bloomberg News (April 23), http://www.bloomberg.com/news/2013-04-23/fake-report-erasing-136-billionshows-market-s-fragility.html. 


\section{Table 1}

\section{Descriptive statistics}

The sample period covers 21 months from June 1996 to February 1998, centered with the event month of April 1997 representing the time of the TSX floor closure. We partition the sample period to form two sub-periods: Period 1 for the 10 months before and Period 2 for the 10 months after the event month. Our sample comprises of the population of 75 stocks that were actively traded (trades during each trading day) throughout the sample period with at least 30 observations in each month necessary to estimate the equation 1. SHRP (adjusted $\mathrm{R}^{2}$ from regression 1, inverse indicator of market efficiency); $A S \_L S B$ (adverse selection estimate using LSB model); $A S \_H S$ (adverse selection estimate using HS model); ADSpread (average dollar spread); AESpread (average effective spread); ARSpread (average relative spread); EFSpread (average effective spread based on 5-minute intervals), RZSpread (average realized spread based on 5-minute intervals), and PImpact (average price impact based on 5-minute interval) based on Hendershott et al., (2011); SVolume (monthly total trading volume in shares); DVolume (monthly total trading volume in dollar); NTrades (monthly total number of trades); Volatility (annualized volatility of daily return based on close-to-close price); Price (average transaction price); $M U$ (arrival rate of informed traders using the EKOP model, described in Section 3.2); Epsilon (arrival rate of uninformed traders); PIN (probability of informed trading). All coefficients have been winsorized at the $1 \%$ levels. * denotes variables that are log transformed. The last two columns report the pvalues from the two-sample t-test and the Wilcoxon-Mann-Whitney test for differences in means and medians respectively between the two sub-periods.

\begin{tabular}{|c|c|c|c|c|c|c|c|c|c|}
\hline & Mean & Median & $\begin{array}{r}\text { Standard } \\
\text { deviation }\end{array}$ & Minimum & Maximum & $\begin{array}{r}\text { Period } 1 \\
\text { Mean }\end{array}$ & $\begin{array}{r}\text { Period } 2 \\
\text { Mean }\end{array}$ & $\begin{array}{r}\text { Difference } \\
\text { in means }\end{array}$ & $\begin{array}{l}\text { Difference } \\
\text { in medians }\end{array}$ \\
\hline SHRP & 0.0524 & 0.0450 & 0.0418 & 0.0000 & 0.1973 & 0.0383 & 0.0683 & $<0.001$ & $<0.001$ \\
\hline$A S \_L S B$ & 0.2091 & 0.2006 & 0.0999 & 0.0440 & 0.5028 & 0.1684 & 0.2498 & $<0.001$ & $<0.001$ \\
\hline$A S \_H S$ & 0.1917 & 0.1874 & 0.0984 & 0.0340 & 0.4669 & 0.1456 & 0.2378 & $<0.001$ & $<0.001$ \\
\hline ADSpread & 0.1183 & 0.0899 & 0.0784 & 0.0338 & 0.4985 & 0.1192 & 0.1173 & 0.6386 & 0.0486 \\
\hline AESpread & 0.1081 & 0.0818 & 0.0698 & 0.0297 & 0.4444 & 0.1024 & 0.1138 & 0.0016 & $<0.001$ \\
\hline ARSpread & 0.0050 & 0.0044 & 0.0026 & 0.0013 & 0.0147 & 0.0051 & 0.0048 & 0.0462 & 0.0159 \\
\hline EFSpread & 0.0021 & 0.0018 & 0.0012 & 0.0006 & 0.0068 & 0.0020 & 0.0021 & 0.0816 & 0.0827 \\
\hline RZSpread & 0.0011 & 0.0010 & 0.0007 & 0.0001 & 0.0039 & 0.0012 & 0.0009 & $<0.001$ & $<0.001$ \\
\hline PImpact & 0.0010 & 0.0008 & 0.0007 & 0.0001 & 0.0035 & 0.0008 & 0.0012 & $<0.001$ & $<0.001$ \\
\hline SVolume* & 15.3782 & 15.4985 & 1.0413 & 12.1200 & 18.4500 & 15.2485 & 15.5078 & $<0.001$ & $<0.001$ \\
\hline DVolume* & 18.5357 & 18.5731 & 1.2735 & 14.2200 & 22.1400 & 18.3560 & 18.7154 & $<0.001$ & $<0.001$ \\
\hline NTrades* & 7.8458 & 7.8012 & 0.8451 & 5.8500 & 10.9400 & 7.6893 & 8.0023 & $<0.001$ & $<0.001$ \\
\hline Volatility & 0.2781 & 0.2435 & 0.1466 & 0.0806 & 0.0908 & 0.2404 & 0.3159 & $<0.001$ & $<0.001$ \\
\hline Price & 29.2168 & 26.0258 & 18.7479 & 2.8200 & 99.9400 & 27.9046 & 30.5289 & 0.007 & 0.003 \\
\hline$M U^{*}$ & 3.9203 & 3.8256 & 0.8457 & 2.3829 & 6.0801 & 3.7756 & 4.0653 & $<0.001$ & $<0.001$ \\
\hline Epsilon* & 3.9057 & 3.8683 & 0.8612 & 2.1860 & 6.0008 & 3.7438 & 4.0677 & $<0.001$ & $<0.001$ \\
\hline PIN & 0.1825 & 0.1718 & 0.0729 & 0.0397 & 0.4277 & 0.1931 & 0.1720 & $<0.001$ & $<0.001$ \\
\hline
\end{tabular}


Figure 1

Market efficiency over time

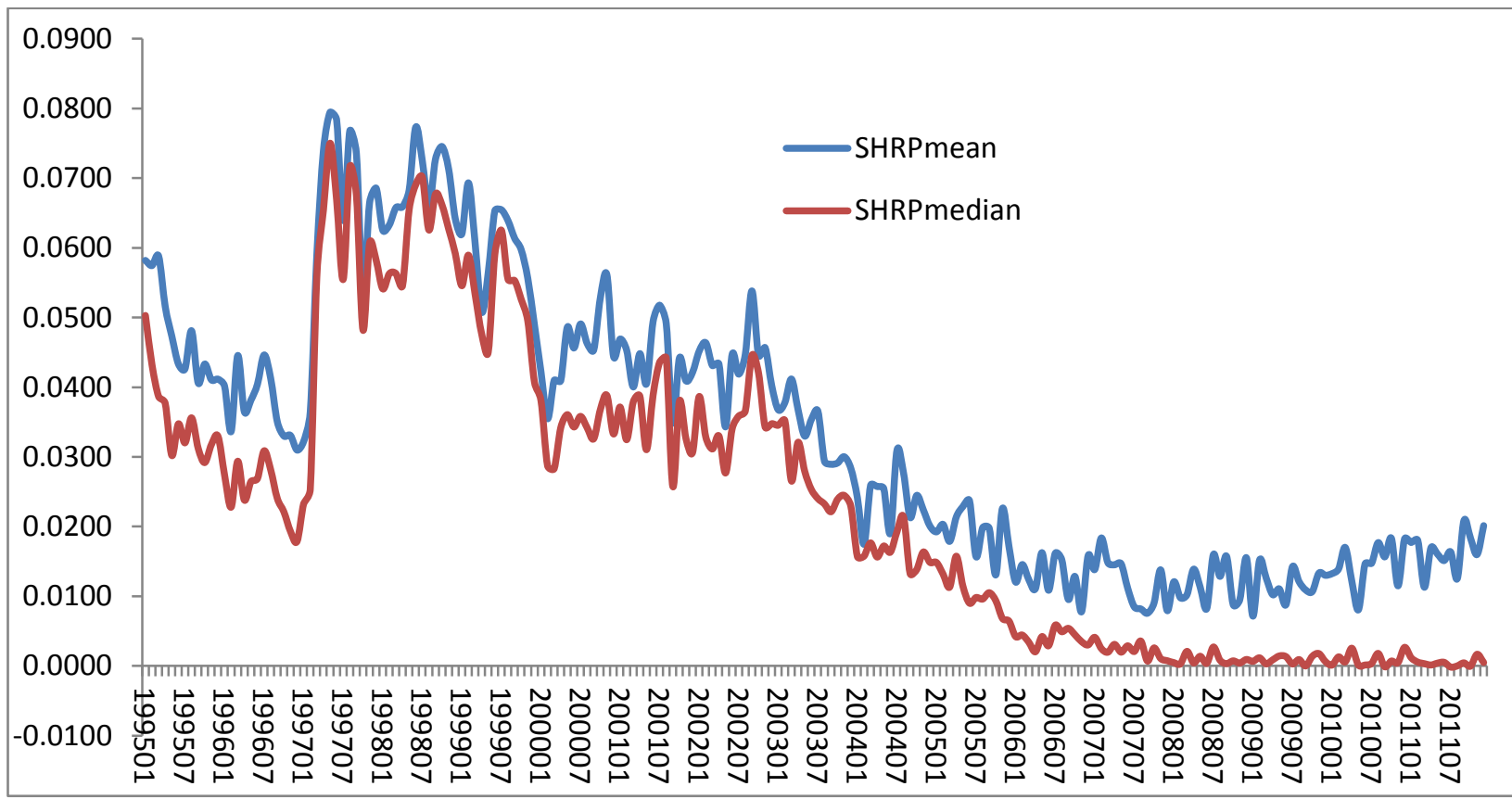




\section{Table 2}

Market efficiency over time

The extended sample period covers 120 months from January 1995 to December 2004, over which 39 TSX securities traded continuously (with at least 30 observations in each month necessary to estimate the SHRP). The last two columns report the p-values from tests of differences in means and medians (based on the two-sample t-test and the Wilcoxon-Mann Whitney test respectively) between years following the floor closure (Y0) and the year prior to floor closure.

\begin{tabular}{cccccc} 
& Period & SHRP & SHRP & \multicolumn{2}{c}{ p-values (differences) } \\
Year & Mean & Median & Means & Medians \\
\hline Y-1 & April 1996 - March 1997 & 0.0346 & 0.0218 & & \\
Y 0 & April 1997 (floor closure) & & & & \\
Y+1 & May 1997 - April 1998 & 0.0637 & 0.0546 & $<0.001$ & $<0.001$ \\
Y+2 & May 1998 - April 1999 & 0.0613 & 0.0563 & $<0.001$ & $<0.001$ \\
Y+3 & May 1999 - April 2000 & 0.0475 & 0.0424 & $<0.001$ & $<0.001$ \\
Y+4 & May 2000 - April 2001 & 0.0385 & 0.0326 & 0.076 & $<0.001$ \\
Y+5 & May 2001 - April 2002 & 0.0355 & 0.0278 & 0.686 & 0.001 \\
Y+6 & May 2002 - April 2003 & 0.0325 & 0.0273 & 0.385 & 0.003 \\
Y+7 & May 2003 - April 2004 & 0.0243 & 0.0182 & $<0.001$ & 0.050 \\
n & & 39 & 39 & & \\
\hline
\end{tabular}


Table 3

Correlation matrix

This table shows the correlation matrix of the regression variables. The sample period covers 21 months from June 1996 to February 1998 , centered with the event month of April 1997 representing the time of the TSX floor closure. We partition the sample period to form two subperiods: Period 1 for the 10 months before and Period 2 for the 10 months after the event month. Our sample comprises of 75 actively traded TSX stocks that were active with trades reported for every trading day throughout our sample period. All variables are the same as described in the preceding tables. Pearson (above diagonal) and Spearman (below diagonal) correlation significant at the 0.05 level is indicated by an asterisk. Variables DVolume, NTrade, MU, Epsilon and Price are log transformed. Panel A shows based on 1,500 firm-month observations, except for correlations with $M U$, Epsilon and PIN, which are based on 1,463 firm-month observations. Panel B reports Pearson (above diagonal) and Spearman (below diagonal) correlations of changes in the variables between Period 1 and Period 2 (based on averages for each of the 75 stocks in the sample).

Panel A

\begin{tabular}{lcccccccccccccc}
\hline & SHRP & AS_LSB & EFSpread & RZSpread & PImpact & DVolume & NTrades & Volatility & Price & MU & Epsilon & PIN \\
\hline SHRP & 1.000 & $0.439 *$ & $0.366 *$ & $0.132 *$ & $0.495 *$ & $-0.408 *$ & $-0.420 *$ & $0.060 *$ & $-0.237 *$ & $-0.360 *$ & $-0.416 *$ & $0.089 *$ \\
AS_LSB & $0.493 *$ & 1.000 & $0.202 *$ & $-0.063 *$ & $0.415 *$ & -0.076 & $-0.307 *$ & $0.213 *$ & $0.127 *$ & $-0.237 *$ & $-0.293 *$ & $-0.066 *$ \\
EFSpread & $0.374 *$ & $0.198 *$ & 1.000 & $0.844 *$ & $0.834 *$ & $-0.732 *$ & $-0.584 *$ & $0.431 *$ & $-0.688 *$ & $-0.404 *$ & $-0.596 *$ & $0.265 *$ \\
RZSpread & $0.122 *$ & $-0.073 *$ & $0.848 *$ & 1.000 & $0.421 *$ & $-0.656 *$ & $-0.555 *$ & $0.229 *$ & $-0.636 *$ & $-0.409 *$ & $-0.568 *$ & $0.286 *$ \\
PImpact & $0.529 *$ & $0.435 *$ & $0.804 *$ & $0.413 *$ & 1.000 & $-0.582 *$ & $-0.433 *$ & $0.495 *$ & $-0.523 *$ & $-0.275 *$ & $-0.441 *$ & $0.174 *$ \\
DVolume & $-0.361 *$ & -0.056 & $-0.799 *$ & $-0.721 *$ & $-0.579 *$ & 1.000 & $0.796 *$ & 0.000 & $0.574 *$ & $0.658 *$ & $0.801 *$ & $-0.311 *$ \\
NTrades & $-0.364 *$ & $-0.287 *$ & $-0.652 *$ & $-0.603 *$ & $-0.444 *$ & $0.799 *$ & 1.000 & $0.163 *$ & $0.268 *$ & $0.873 *$ & $0.992 *$ & $-0.265 *$ \\
Volatility & $0.099 *$ & $0.263 *$ & $0.374 *$ & $0.179 *$ & $0.476 *$ & 0.020 & $0.151 *$ & 1.000 & $-0.246 *$ & $0.341 *$ & $0.147 *$ & 0.040 \\
Price & $-0.228 *$ & $0.141 *$ & $-0.660 *$ & $-0.631 *$ & $-0.463 *$ & $0.570 *$ & $0.268 *$ & $-0.190 *$ & 1.000 & $0.140 *$ & $0.281 *$ & $-0.205 *$ \\
MU & $-0.319 *$ & $-0.224 *$ & $-0.468 *$ & $-0.459 *$ & $-0.286 *$ & $0.658 *$ & $0.879 *$ & $0.319 *$ & $0.152 *$ & 1.000 & $0.859 *$ & $-0.169 *$ \\
Epsilon & $-0.359 *$ & $-0.275 *$ & $-0.659 *$ & $-0.612 *$ & $-0.446 *$ & $0.803 *$ & $0.994 *$ & $0.145 *$ & $0.278 *$ & $0.866 *$ & 1.000 & $-0.365 *$ \\
PIN & 0.034 & $-0.066 *$ & $0.306 *$ & $0.313 *$ & $0.177 *$ & $-0.340 *$ & $-0.307 *$ & 0.025 & $-0.222 *$ & $-0.224 *$ & $-0.384 *$ & 1.000 \\
\hline
\end{tabular}


Table 3 - continued

Panel B

\begin{tabular}{|c|c|c|c|c|c|c|c|c|c|c|c|c|}
\hline & $\begin{array}{r}\Delta \\
S H R P \\
\end{array}$ & $\begin{array}{r}\Delta \\
A S \_L S B \\
\end{array}$ & $\begin{array}{r}\Delta \\
\text { EFSpread } \\
\end{array}$ & $\begin{array}{r}\Delta \\
\text { RZSpread } \\
\end{array}$ & $\begin{array}{r}\Delta \\
\text { PImpact } \\
\end{array}$ & $\begin{array}{r}\Delta \\
\text { DVolume } \\
\end{array}$ & $\begin{array}{r}\Delta \\
\text { NTrades } \\
\end{array}$ & $\begin{array}{r}\Delta \\
\text { Volatility } \\
\end{array}$ & $\begin{array}{r}\Delta \\
\text { Price } \\
\end{array}$ & $\begin{array}{r}\Delta \\
M U \\
\end{array}$ & $\begin{array}{r}\Delta \\
\text { Epsilon } \\
\end{array}$ & $\begin{array}{r}\Delta \\
P I N \\
\end{array}$ \\
\hline$\triangle S H R P$ & 1.000 & $0.610 *$ & $0.314 *$ & -0.129 & $0.630 *$ & $-0.231 *$ & $-0.412 *$ & 0.081 & $-0.292 *$ & $-0.404 *$ & $-0.416 *$ & 0.046 \\
\hline$\triangle A S \_L S B$ & $0.568 *$ & 1.000 & 0.049 & -0.260 & $0.360 *$ & 0.075 & $-0.387 *$ & -0.004 & 0.048 & $-0.392 *$ & $-0.391 *$ & -0.149 \\
\hline$\triangle E F S p r e a d$ & $0.312 *$ & 0.031 & 1.000 & $0.754 *$ & $0.749 *$ & $-0.694 *$ & $-0.453 *$ & $0.547 *$ & $-0.328 *$ & $-0.358 *$ & $-0.467 *$ & 0.154 \\
\hline$\triangle R Z S p r e a d$ & -0.152 & $-0.246 *$ & $0.693 *$ & 1.000 & 0.138 & $-0.502 *$ & $-0.310 *$ & $0.340 *$ & -0.121 & $-0.224 *$ & $-0.321 *$ & 0.108 \\
\hline$\triangle$ PImpact & $0.578 *$ & $0.346 *$ & $0.656 *$ & 0.067 & 1.000 & $-0.537 *$ & $-0.381 *$ & $0.474 *$ & $-0.371 *$ & $-0.341 *$ & $-0.396 *$ & 0.138 \\
\hline$\Delta D$ Volume & $-0.241 *$ & -0.052 & $-0.621 *$ & $-0.489 *$ & $-0.421 *$ & 1.000 & $0.450 *$ & $-0.376 *$ & $0.366 *$ & $0.395 *$ & $0.472 *$ & -0.176 \\
\hline$\triangle N T r a d e s$ & $-0.427 *$ & $-0.390 *$ & $-0.462 *$ & $-0.284 *$ & $-0.340 *$ & $0.446 *$ & 1.000 & 0.148 & -0.120 & $0.884 *$ & $0.983 *$ & -0.151 \\
\hline$\Delta$ Volatility & 0.076 & -0.001 & $0.369 *$ & $0.255 *$ & $0.403 *$ & $-0.297 *$ & 0.181 & 1.000 & $-0.449 *$ & $0.233 *$ & 0.143 & 0.146 \\
\hline$\Delta$ Price & $-0.298 *$ & -0.005 & $-0.437 *$ & $-0.275 *$ & $-0.455 *$ & $0.473 *$ & -0.074 & $-0.502 *$ & 1.000 & -0.072 & -0.079 & -0.217 \\
\hline$\Delta M U$ & $-0.445 *$ & $-0.376 *$ & $-0.374 *$ & -0.214 & $-0.309 *$ & $0.416 *$ & $0.872 *$ & $0.258 *$ & -0.035 & 1.000 & $0.877 *$ & 0.167 \\
\hline$\triangle$ Epsilon & $-0.413 *$ & $-0.392 *$ & $-0.460 *$ & $-0.276 *$ & $-0.356 *$ & $0.453 *$ & $0.987 *$ & 0.182 & -0.067 & $0.871 *$ & 1.000 & 0.014 \\
\hline$\triangle P I N$ & 0.030 & -0.079 & 0.163 & 0.095 & $0.257 *$ & -0.149 & 0.051 & 0.116 & -0.182 & 0.082 & -0.044 & 1.000 \\
\hline
\end{tabular}


Table 4

Determinants of changes in market efficiency

This table shows the regression results of equation (8). Our sample comprises of 75 actively traded TSX stocks that were active with trades reported for every trading day throughout our sample period. All variables are the same as described in the preceding tables, with change in the variable denoted by $\Delta$ preceding the variable name. Numbers in parentheses beneath the coefficients are the $t$-statistics. *,**, and $* * *$ denotes the two-tail significance at the $10 \%, 5 \%$ and $1 \%$ levels respectively.

Panel A: Bivariate regressions

\begin{tabular}{|c|c|c|c|c|c|c|c|c|c|c|c|}
\hline & $(1)$ & (2) & (3) & (4) & $(5)$ & $(6)$ & $(7)$ & $(8)$ & (9) & $(10)$ & $(11)$ \\
\hline Intercept & $\begin{array}{l}0.007 \\
(1.59)\end{array}$ & $\begin{array}{l}0.028 * * * \\
(8.41)\end{array}$ & $\begin{array}{l}0.027 * * * \\
(6.66)\end{array}$ & $\begin{array}{l}0.013 * * * \\
(3.54)\end{array}$ & $\begin{array}{l}0.035 * * * \\
(8.25)\end{array}$ & $\begin{array}{l}0.041 * * * \\
(9.66)\end{array}$ & $\begin{array}{l}0.028 * * * \\
(5.22)\end{array}$ & $\begin{array}{l}0.033 * * * \\
(9.38)\end{array}$ & $\begin{array}{l}0.039 * * * \\
(9.85)\end{array}$ & $\begin{array}{l}0.042 * * * \\
(9.53)\end{array}$ & $\begin{array}{l}0.031 \text { *** } \\
(7.70)\end{array}$ \\
\hline$\triangle A S \_L S B$ & $\begin{array}{l}0.281 * * * \\
(6.57)\end{array}$ & & & & & & & & & & \\
\hline$\triangle E F S p r e a d$ & & $\begin{array}{l}16.549 * * * \\
(2.82)\end{array}$ & & & & & & & & & \\
\hline$\triangle R Z S p r e a d$ & & & $\begin{array}{r}-10.695 \\
(-1.12)\end{array}$ & & & & & & & & \\
\hline$\triangle$ PImpact & & & & $\begin{array}{l}50.368 * * * \\
(6.93)\end{array}$ & & & & & & & \\
\hline$\Delta D$ Volume & & & & & $\begin{array}{l}-0.015 * * \\
(-2.03)\end{array}$ & & & & & & \\
\hline$\triangle N T r a d e s$ & & & & & & $\begin{array}{l}-0.034 * * * \\
(-3.86)\end{array}$ & & & & & \\
\hline$\Delta$ Volatility & & & & & & & $\begin{array}{l}0.036 \\
(0.69)\end{array}$ & & & & \\
\hline$\Delta$ Price & & & & & & & & $\begin{array}{l}-0.001 * * \\
(2.61)\end{array}$ & & & \\
\hline$\Delta M U$ & & & & & & & & & $\begin{array}{l}-0.030 * * * \\
(-3.78)\end{array}$ & & \\
\hline AEpsilon & & & & & & & & & & $\begin{array}{l}-0.036 \text { *** } \\
(-3.91)\end{array}$ & \\
\hline$\triangle P I N$ & & & & & & & & & & & $\begin{array}{l}0.036 \\
(0.39)\end{array}$ \\
\hline Adjusted $\mathrm{R}^{2}$ & $36.32 \%$ & $8.62 \%$ & $0.33 \%$ & $38.85 \%$ & $4.05 \%$ & $15.84 \%$ & $0.65 \%$ & $7.26 \%$ & $15.20 \%$ & $16.20 \%$ & $0.21 \%$ \\
\hline
\end{tabular}


Table 4 - continued

Panel B: Multivariate regressions

\begin{tabular}{|c|c|c|c|c|c|c|c|c|c|}
\hline & $(12)$ & (13) & $(14)$ & $(15)$ & $(16)$ & $(17)$ & $(18)$ & $(19)$ & $(20)$ \\
\hline Intercept & $\begin{array}{l}0.019 * * * \\
(2.99)\end{array}$ & $\begin{array}{l}0.020 * * * \\
(3.09)\end{array}$ & $\begin{array}{l}0.019 * * * \\
(3.05)\end{array}$ & $\begin{array}{l}0.019 * * * \\
(2.87)\end{array}$ & $\begin{array}{l}0.000 \\
(0.18)\end{array}$ & $\begin{array}{l}0.013 * * \\
(2.25)\end{array}$ & $\begin{array}{l}0.014 * * \\
(2.33)\end{array}$ & $\begin{array}{l}0.012 * * \\
(2.09)\end{array}$ & $\begin{array}{l}0.013 * * \\
(2.16)\end{array}$ \\
\hline$\triangle A S \_L S B$ & $\begin{array}{l}0.269 * * * \\
(5.99)\end{array}$ & $\begin{array}{l}0.270 * * * \\
(5.98)\end{array}$ & $\begin{array}{l}0.278 * * * \\
(6.20)\end{array}$ & $\begin{array}{l}0.280 * * * \\
(6.07)\end{array}$ & $\begin{array}{l}0.203 * * * \\
(5.28)\end{array}$ & $\begin{array}{l}0.175 * * * \\
(3.81)\end{array}$ & $\begin{array}{l}0.176 * * * \\
(3.81)\end{array}$ & $\begin{array}{l}0.190 * * * \\
(4.14)\end{array}$ & $\begin{array}{l}0.183 \text { *** } \\
(3.85)\end{array}$ \\
\hline$\triangle E F S p r e a d$ & $\begin{array}{r}11.149 \\
(1.48)\end{array}$ & $\begin{array}{r}10.317 \\
(1.35)\end{array}$ & $\begin{array}{r}11.912 \\
(1.63)\end{array}$ & $\begin{array}{r}11.976 \\
(1.57)\end{array}$ & & & & & \\
\hline$\triangle R Z S p r e a d$ & & & & & & $\begin{array}{l}-7.042 \\
(-0.85)\end{array}$ & $\begin{array}{l}-7.582 \\
(-0.90)\end{array}$ & $\begin{array}{l}-4.984 \\
(-0.61)\end{array}$ & $\begin{array}{l}-6.204 \\
(-0.73)\end{array}$ \\
\hline$\triangle P$ Impact & & & & & $\begin{array}{l}37.693 * * * \\
(5.66)\end{array}$ & $\begin{array}{c}37.541 * * * \\
(4.17)\end{array}$ & $\begin{array}{c}36.678 * * * \\
(4.01)\end{array}$ & $\begin{array}{l}38.403 * * * \\
(4.19)\end{array}$ & $\begin{array}{l}37.888 * * * \\
(4.14)\end{array}$ \\
\hline$\Delta D$ Volume & $\begin{array}{l}-0.002 \\
(-0.29)\end{array}$ & $\begin{array}{l}-0.002 \\
(-0.18)\end{array}$ & $\begin{array}{l}-0.003 \\
(-0.35)\end{array}$ & $\begin{array}{l}-0.003 \\
(-0.38)\end{array}$ & & $\begin{array}{c}0.002 \\
(0.24)\end{array}$ & $\begin{array}{r}0.002 \\
(0.31)\end{array}$ & $\begin{array}{r}0.000 \\
(0.02)\end{array}$ & $\begin{array}{l}0.001 \\
(0.14)\end{array}$ \\
\hline$\triangle N T r a d e s$ & $\begin{array}{l}-0.007 \\
(-0.64)\end{array}$ & $\begin{array}{l}-0.009 \\
(-0.80)\end{array}$ & & & & $\begin{array}{l}-0.011 \\
(-1.05)\end{array}$ & $\begin{array}{l}-0.012 \\
(-1.17)\end{array}$ & & \\
\hline$\Delta$ Volatility & $\begin{array}{l}-0.080 \\
(-1.49)\end{array}$ & $\begin{array}{l}-0.076 \\
(-1.39)\end{array}$ & $\begin{array}{l}-0.085 \\
(-1.49)\end{array}$ & $\begin{array}{l}-0.089 \\
(-1.60)\end{array}$ & & $\begin{array}{l}-0.088 \\
(-1.85)\end{array}$ & $\begin{array}{l}-0.085 \\
(-1.75)\end{array}$ & $\begin{array}{l}-0.098 * \\
(-1.92)\end{array}$ & $\begin{array}{l}-0.094 * \\
(-1.90)\end{array}$ \\
\hline$\triangle$ Price & $\begin{array}{l}-0.001 * * * \\
(-3.36)\end{array}$ & $\begin{array}{l}-0.001 * * * \\
(-3.28)\end{array}$ & $\begin{array}{l}-0.001 * * * \\
(-3.19)\end{array}$ & $\begin{array}{l}-0.001 * * * \\
(-3.17)\end{array}$ & & $\begin{array}{l}-0.001 * * * \\
(-2.94)\end{array}$ & $\begin{array}{l}-0.001 * * * \\
(-2.88)\end{array}$ & $\begin{array}{l}-0.001 * * * \\
(-2.69)\end{array}$ & $\begin{array}{l}-0.001 * * * \\
(-2.76)\end{array}$ \\
\hline$\triangle M U$ & & & $\begin{array}{l}-0.004 \\
(-0.44)\end{array}$ & & & & & $\begin{array}{l}-0.005 \\
(-0.55)\end{array}$ & \\
\hline AEpsilon & & & & $\begin{array}{l}-0.004 \\
(-0.33)\end{array}$ & & & & & $\begin{array}{l}-0.008 \\
(-0.76)\end{array}$ \\
\hline$\triangle P I N$ & & $\begin{array}{r}0.055 \\
(0.81)\end{array}$ & $\begin{array}{r}0.050 \\
(0.73)\end{array}$ & $\begin{array}{r}0.043 \\
(0.65)\end{array}$ & & & $\begin{array}{r}0.040 \\
(0.64)\end{array}$ & $\begin{array}{r}0.032 \\
(0.51)\end{array}$ & $\begin{array}{r}0.024 \\
(0.39)\end{array}$ \\
\hline Adjusted $\mathrm{R}^{2}$ & $50.77 \%$ & $50.52 \%$ & $50.20 \%$ & $50.14 \%$ & $55.31 \%$ & $60.66 \%$ & $60.31 \%$ & $59.68 \%$ & $59.85 \%$ \\
\hline
\end{tabular}


Table 4 - continued

Panel C: Multivariate regressions - sensitivities to spreads

\begin{tabular}{|c|c|c|c|c|c|c|c|c|c|}
\hline & $(12 a)$ & $(12 b)$ & $(12 c)$ & $(14 a)$ & $(14 b)$ & $(14 c)$ & $(15 a)$ & $(15 b)$ & $(15 c)$ \\
\hline Intercept & $\begin{array}{l}0.022 * * * \\
(3.43)\end{array}$ & $\begin{array}{l}0.021 * * * \\
(3.23)\end{array}$ & $\begin{array}{l}0.022 * * * \\
(3.46)\end{array}$ & $\begin{array}{l}0.021 * * * \\
(3.35)\end{array}$ & $\begin{array}{l}0.022 * * * \\
(3.37)\end{array}$ & $\begin{array}{l}0.020 * * * \\
(3.20)\end{array}$ & $\begin{array}{l}0.021 * * * \\
(3.14)\end{array}$ & $\begin{array}{l}0.020 * * * \\
(3.34)\end{array}$ & $\begin{array}{l}0.022 * * * \\
(3.40)\end{array}$ \\
\hline$\triangle A S \_L S B$ & $\begin{array}{l}0.260 * * * \\
(5.52)\end{array}$ & $\begin{array}{l}0.265 * * * \\
(5.80)\end{array}$ & $\begin{array}{l}0.255 * * * \\
(5.41)\end{array}$ & $\begin{array}{l}0.274 * * * \\
(5.90)\end{array}$ & $\begin{array}{l}0.270 \text { *** } \\
(5.57)\end{array}$ & $\begin{array}{l}0.275 * * * \\
(6.05)\end{array}$ & $\begin{array}{l}0.274 \text { *** } \\
(5.86)\end{array}$ & $\begin{array}{l}0.271 \text { *** } \\
(5.79)\end{array}$ & $\begin{array}{l}0.265 * * * \\
(5.44)\end{array}$ \\
\hline$\triangle A D$ Spread & $\begin{array}{l}-0.004 \\
(-0.05)\end{array}$ & & & $\begin{array}{l}0.015 \\
(0.20)\end{array}$ & $\begin{array}{l}0.001 \\
(0.01)\end{array}$ & & & & \\
\hline$\triangle A E S p r e a d$ & & $\begin{array}{l}0.062 \\
(0.64)\end{array}$ & & & & $\begin{array}{l}0.079 \\
(0.83)\end{array}$ & $\begin{array}{l}0.069 \\
(0.70)\end{array}$ & & \\
\hline$\triangle A R S p r e a d$ & & & $\begin{array}{l}-1.135 \\
(-0.40)\end{array}$ & & & & & $\begin{array}{l}-0.446 \\
(-0.16)\end{array}$ & $\begin{array}{l}-0.952 \\
(-0.33)\end{array}$ \\
\hline$\Delta D$ Volume & $\begin{array}{l}-0.006 \\
(-0.79)\end{array}$ & $\begin{array}{l}-0.007 \\
(-0.87)\end{array}$ & $\begin{array}{l}-0.007 \\
(-0.89)\end{array}$ & $\begin{array}{l}-0.008 \\
(-1.04)\end{array}$ & $\begin{array}{l}-0.007 \\
(-0.87)\end{array}$ & $\begin{array}{l}-0.008 \\
(-1.03)\end{array}$ & $\begin{array}{l}-0.008 \\
(-0.95)\end{array}$ & $\begin{array}{l}-0.008 \\
(-1.02)\end{array}$ & $\begin{array}{l}-0.008 \\
(-0.93)\end{array}$ \\
\hline$\triangle N T r a d e s$ & $\begin{array}{l}-0.015 \\
(-1.36)\end{array}$ & $\begin{array}{l}-0.012 \\
(-1.15)\end{array}$ & $\begin{array}{l}-0.017 \\
(-1.49)\end{array}$ & & & & & & \\
\hline$\triangle$ Volatility & $\begin{array}{l}-0.035 \\
(-1.76)\end{array}$ & $\begin{array}{l}-0.041 \\
(-0.89)\end{array}$ & $\begin{array}{l}-0.025 \\
(-0.47)\end{array}$ & $\begin{array}{l}-0.037 \\
(-0.74)\end{array}$ & $\begin{array}{l}-0.040 \\
(-0.83)\end{array}$ & $\begin{array}{l}-0.041 \\
(-0.84)\end{array}$ & $\begin{array}{l}-0.046 \\
(-0.97)\end{array}$ & $\begin{array}{l}-0.030 \\
(-0.55)\end{array}$ & $\begin{array}{l}-0.030 \\
(-0.54)\end{array}$ \\
\hline$\Delta$ Price & $\begin{array}{l}-0.001 * * * \\
(-2.91)\end{array}$ & $\begin{array}{l}-0.001 * * * \\
(-3.29)\end{array}$ & $\begin{array}{l}-0.001 * * * \\
(-3.41)\end{array}$ & $\begin{array}{l}-0.001 * * * \\
(-2.67)\end{array}$ & $\begin{array}{l}-0.001 * * * \\
(-2.70)\end{array}$ & $\begin{array}{l}-0.001 * * * \\
(-3.05)\end{array}$ & $\begin{array}{l}-0.001 * * * \\
(-3.10)\end{array}$ & $\begin{array}{l}-0.001 * * * \\
(-3.04)\end{array}$ & $\begin{array}{l}-0.001 * * * \\
(-3.16)\end{array}$ \\
\hline$\triangle M U$ & & & & $\begin{array}{l}-0.009 \\
(-1.06)\end{array}$ & & $\begin{array}{l}-0.009 \\
(-0.93)\end{array}$ & & $\begin{array}{l}-0.011 \\
(-1.14)\end{array}$ & \\
\hline$\triangle$ Epsilon & & & & & $\begin{array}{l}-0.013 \\
(-1.08)\end{array}$ & & $\begin{array}{l}-0.010 \\
(-0.87)\end{array}$ & & $\begin{array}{l}-0.015 \\
(-1.21)\end{array}$ \\
\hline$\triangle P I N$ & & & & $\begin{array}{r}0.062 \\
(0.90)\end{array}$ & $\begin{array}{r}0.047 \\
(0.68)\end{array}$ & $\begin{array}{r}0.060 \\
(0.86)\end{array}$ & $\begin{array}{l}0.046 \\
(0.67)\end{array}$ & $\begin{array}{l}0.065 \\
(0.93)\end{array}$ & $\begin{array}{l}0.047 \\
(0.69)\end{array}$ \\
\hline Adjusted $\mathrm{R}^{2}$ & $49.19 \%$ & $49.49 \%$ & $49.30 \%$ & $48.26 \%$ & $48.30 \%$ & $48.76 \%$ & $48.68 \%$ & $48.25 \%$ & $48.39 \%$ \\
\hline
\end{tabular}

